\title{
Research On the Factors for Successful Diffusion of Chinese Neologism
}

\author{
Dongmei Zhou \\ School of foreign languages, Wuhan Textile University ,Hubei, China \\ ttzhou402@163.com
}

Keywords: Neologism, Diffusion, Factor

\begin{abstract}
This paper conducts an empirical investigation on 30 examples of both successful and unsuccessful diffusions and analyzes quantitatively and qualitatively. The research reveals that the flexibility of word's transformation, the range of the audience and the degree of the force of the media are the most important factors of neologism diffusion.
\end{abstract}

\section{Introduction}

With the rapid development of society, language, as the indispensible part of our daily life, also enjoys fast changes today. And numerous new words or neologism appear nearly everywhere and are spread widely in a crazing speed. This is partly due to the fact that newspapers, magazines, TV, radio, and the internet create a favorable environment for the information explosion.

The neologism refers to a newly coined term, word, or phrase that may be in the process of entering common use, but may be not accepted into mainstream language.[1] There are many ways to invent a new word. One of the most common modes is to borrow foreign words. As the global communication goes deeper into our work and life, more and more foreign brands become worldly known and finally become hot new words. What's more, new theories in science and new policies in politics also bring a lot of new vocabularies that gradually be recognized by citizens.

However, not every neologism can survive longer in this age since information exchanges are so fast in today’s world. According to "The Report of Chinese Language State in 2011”, which was published by Chinese Ministry of Education in 2012, there were 594 new words and phrases newly appearing in Chinese language in the year of 2011.[2] Nevertheless, many neologisms that occurred during the former years have disappeared in our daily life. Among the 2977 representative neologisms generated from 2006 to 2010 , only $41 \%$ of them were successfully remained while $34 \%$ quickly disappeared in peoples talking and writing.[2] The research mainly focuses on the Chinese new words or phrases that occurred after the year 2000. In this paper, a collection will be used to gain data and to do some quantitative and qualitative analysis. The subjects of the whole collection also share the same range of the whole research. It is hoped that the collection can be kind of reference to more neologisms in wider range and the factors that influence the effect of word-spread can be found finally.

\section{Research Design}

The collection in this research chooses 40 new words occurred after the year 2000 and the specific contexts for each word. Among the 40 neologisms, 20 of them are popularly used nowadays and are frequently seen and used in our daily life while another 20 are failed to be 
diffused. The 20 popularly-used ones are called Group 1 (hereinafter referred to G1) and another 30 that haven't been successfully spread are called Group 2 (hereinafter referred to G2). All the materials come from different media including newspaper, journalism, TV series, forums, internet comments, advertisements and blogs. There are totally six items listed to analyze different factors for neologisms diffusion. The positive ones are marked as 1 and the negative as 2 .

\section{Quantitative Analysis of Neologisms}

\subsection{Feasibility of the Collection Research}

Since a collection of 20 or more subjects is meaningful in statistics, this collection used in this paper can be seen feasible and effective. The collection tries to trace the usage of neologisms back to the origin state. For the subjects in G1, it is really difficult to find out the origin or the generation process of today's hot words since the words are so popular that the origin is relatively easily forgettable and less important to the public in communication. But there must be some close relations or similarities for both cold and hot diffusion phases of a buzzword. Therefore, the popular usages of the words in G1 are gathered as the reappearance of the original states. For many words in G2, the original usages of the subjects have already been founded while the rest of them share the same way as those in G1.

\subsection{Result of the Statistics}

According to the aspects mentioned above, the collections that match the standards are summed respectively in G1 and G2. The number of each item is taken down into a table. The result of the statistics is as follows.

Table 1:

\begin{tabular}{|c|c|c|c|c|c|c|}
\hline & \multicolumn{2}{|l|}{ Linguistics } & \multicolumn{3}{|c|}{ Communication } & \multirow{3}{*}{$\begin{array}{l}\text { Media } \\
\text { Force of } \\
\text { media }\end{array}$} \\
\hline & \multirow{2}{*}{$\begin{array}{l}\text { Suitability } \\
\text { of the } \\
\text { context }\end{array}$} & \multirow{2}{*}{$\begin{array}{l}\text { Flexibility } \\
\text { of the } \\
\text { trans- } \\
\text { formation }\end{array}$} & \multicolumn{2}{|c|}{ Participants } & \multirow[b]{2}{*}{$\begin{array}{l}\text { Relation } \\
\text { with } \\
\text { society } \\
\text { and } \\
\text { culture }\end{array}$} & \\
\hline & & & $\begin{array}{l}\text { Special } \\
\text { subjects }\end{array}$ & $\begin{array}{l}\text { Range of } \\
\text { audience }\end{array}$ & & \\
\hline G1 & 19 & 21 & 7 & 28 & 18 & 22 \\
\hline G2 & 17 & 3 & 8 & 18 & 14 & 8 \\
\hline
\end{tabular}

Table 2:

\begin{tabular}{|c|c|c|c|c|c|c|c|}
\hline & & \multicolumn{2}{|c|}{ Linguistics } & \multicolumn{3}{c|}{ Communication } & Media \\
\hline $\begin{array}{c}\text { Word(Chinese } \\
\text { pinying) }\end{array}$ & $\begin{array}{c}\text { Grou } \\
\mathrm{p}\end{array}$ & $\begin{array}{c}\text { Suitability } \\
\text { of the } \\
\text { context }\end{array}$ & $\begin{array}{c}\text { Flexibility } \\
\text { of the trans- } \\
\text { formation }\end{array}$ & $\begin{array}{c}\text { Special } \\
\text { Subjects }\end{array}$ & $\begin{array}{c}\text { Relation } \\
\text { of } \\
\text { with } \\
\text { audienc } \\
\text { e }\end{array}$ & $\begin{array}{c}\text { Fociety } \\
\text { and } \\
\text { culture }\end{array}$ & $\begin{array}{c}\text { Force of } \\
\text { media }\end{array}$ \\
\hline pindie & 1 & 1 & 1 & 1 & 1 & 1 & 1 \\
\hline zhongguomeng & 1 & 1 & 1 & 2 & 1 & 1 & 2 \\
\hline fenghuangnan & 1 & 2 & 2 & 2 & 1 & 2 & 1 \\
\hline paizhuan & 1 & 2 & 2 & 2 & 1 & 2 & 1 \\
\hline shengnu & 1 & 1 & 2 & 2 & 1 & 1 & 1 \\
\hline caogen & 1 & 1 & 1 & 2 & 1 & 1 & 2 \\
\hline gangpiao & 1 & 1 & 1 & 2 & 1 & 1 & 1 \\
\hline
\end{tabular}




\begin{tabular}{|c|c|c|c|c|c|c|c|}
\hline geili & 1 & 1 & 1 & 2 & 1 & 1 & 1 \\
\hline HOLDzhu & 1 & 1 & 1 & 1 & 1 & 1 & 1 \\
\hline daren & 1 & 1 & 1 & 2 & 1 & 1 & 1 \\
\hline weishidai & 1 & 1 & 1 & 2 & 1 & 1 & 1 \\
\hline gaofushuai & 1 & 1 & 2 & 1 & 1 & 1 & 1 \\
\hline miaosha & 1 & 1 & 1 & 2 & 1 & 2 & 2 \\
\hline diaosi & 1 & 2 & 1 & 2 & 1 & 1 & 1 \\
\hline dajiangyou & 1 & 2 & 1 & 1 & 1 & 1 & 1 \\
\hline tucao & 1 & 2 & 1 & 2 & 1 & 2 & 1 \\
\hline weihe & 1 & 2 & 1 & 2 & 1 & 2 & 2 \\
\hline maimeng & 1 & 2 & 1 & 2 & 1 & 2 & 1 \\
\hline tangqiang & 1 & 2 & 1 & 2 & 1 & 2 & 1 \\
\hline xiaoqingxin & 1 & 1 & 2 & 2 & 1 & 2 & 2 \\
\hline kendie & 1 & 2 & 1 & 2 & 1 & 2 & 1 \\
\hline xueba & 1 & 1 & 2 & 2 & 1 & 2 & 2 \\
\hline wuxie & 2 & 2 & 2 & 1 & 1 & 1 & 1 \\
\hline suhui & 2 & 1 & 2 & 1 & 1 & 1 & 1 \\
\hline linglinruo & 2 & 1 & 2 & 1 & 1 & 1 & 1 \\
\hline saiyou & 2 & 2 & 1 & 2 & 1 & 1 & 2 \\
\hline gaoxinlan & 2 & 1 & 2 & 2 & 2 & 1 & 2 \\
\hline wainao & 2 & 2 & 2 & 2 & 2 & 2 & 1 \\
\hline yingba & 2 & 1 & 2 & 1 & 2 & 2 & 2 \\
\hline guoliutiao & 2 & 1 & 2 & 1 & 1 & 1 & 1 \\
\hline chuangzhongli & 2 & 1 & 2 & 2 & 2 & 2 & 2 \\
\hline xinlixiezhuang & 2 & 1 & 2 & 2 & 1 & 1 & 2 \\
\hline lulingfeng & 2 & 1 & 2 & 2 & 2 & 2 & 2 \\
\hline shafake & 2 & 2 & 2 & 2 & 1 & 1 & 2 \\
\hline beizixi & 2 & 1 & 2 & 2 & 2 & 2 & 2 \\
\hline dancikong & 2 & 1 & 2 & 2 & 2 & 2 & 2 \\
\hline gongzhulou & 2 & 2 & 2 & 2 & 2 & 2 & 2 \\
\hline lachouchou & 2 & 1 & 2 & 2 & 2 & 2 & 2 \\
\hline $\begin{array}{c}\text { guangpanxindon } \\
\text { g }\end{array}$ & 2 & 2 & 2 & 2 & 2 & 2 & 2 \\
\hline niunai & 2 & 2 & 2 & 2 & 2 & 2 & 2 \\
\hline Correlation & & $\begin{array}{c}0.06804138 \\
2\end{array}$ & $\begin{array}{c}0.61237243 \\
6\end{array}$ & $\begin{array}{c}-0.0753 \\
8\end{array}$ & 0.57735 & $\begin{array}{c}0.06666 \\
7\end{array}$ & $\begin{array}{c}0.46666 \\
7\end{array}$ \\
\hline
\end{tabular}

During the research, it is found that the range of the audience and the force of the media have an inherent relation to some extent since gaps between the two groups of the figures on these two items in Table 1 are similar to each other. Thus correlation analysis is also given to the two items and the result of it is 0.50037 .

\subsection{Conclusion of the Quantitative Analysis}

According to the table of the statistics, it can be easily found: 
a. In G1, most of the subjects enjoy the suitability of the contexts, flexibility of transformation, big range of audience, close relation with society and culture and become hot by the strong force of the media.

b. More than two thirds of the subjects in G1 own the flexibility of transformation, big range of audience and strong force of media, which accounts for a lot in the total subject. However, the subjects in G2 only have very few in the same three items with a big gap with those in G1.

c. The subjects in both G1 and G2 share the similar big numbers in suitability of the contexts and close relation with society and culture. Besides, both of the two groups have only few and similar number in the aspect of the subjects of communication.

d. From Table 2, big gaps among the six items are obvious, which shows the different effect each item may have on the result of the diffusion of Chinese neologisms. As the bigger the number of correlation is, the more important the item plays a role during the spreading, it is easy to see the work of the flexibility of the word itself, the range of the audience and the force of media.[5]

e. The correlation between the force of the media and the range of the audience shows that there is close relationship between the audience and the media.

\section{Qualitative Analysis of Neologisms}

As the quantitative analysis has put the concentration on the whole collection of neologisms, qualitative analysis chooses one example respectively from the two groups of the collection and the comparison study will also be given to the two specific subjects. The example chosen from G1 is Chinese character "geili" while another one from G2 is "lulingfeng”.

"geili" firstly appeared on the internet on "Baidu Forum" on April 28 $8^{\text {th }}$, 2004. now the word has been so popular in various areas of our life and it has also been given an English form as "geilivable".

"lulingfeng" first come in front of the public as the slogan and the theme of the $10^{\text {th }}$ Association Cultural Festival of Huazhong University of Science and Technology in October 2012.

\subsection{Conclusion of the Qualitative Analysis}

According to the comparative analysis of the two words "geili" and "lulingfeng" from different aspects, some conclusions can be drawn to find out the factors that influence the effect of Chinese neologism diffusion.

\subsubsection{Conclusions from the Similarities of the Two Examples}

Based on the analysis of the words "geili" and "lulingfeng", some similar elements of the word diffusion can be found. Firstly, both of the two words are very properly used in the origin context. Both of the two words play an important role in the different contexts and help convey the meaning of the context accurately and interestingly. Second, both of the two words have a source of a particular kind of culture in a relatively specific area.

\subsubsection{Conclusions from the Differences of the Two Examples}

There are also some differences between the two examples on the neologism diffusions, which are reflected on the flexibility of transformation, the range of audiences and the degree of the media effect. It is easy to find out that the word "geili" can be used in more contexts with more transformation and enjoys larger range of audiences by the strong force of the media. But the word "lulingfeng" has weaker competitiveness on the three aspects.

Therefore, it is proper to infer that the decisive factors for the successful diffusion of Chinese neologisms are the flexibility of transformation of the word itself, the large range of audience and geillivable media for spreading. 


\section{Conclusion}

According to the results of both quantitative and qualitative analysis, it can be found that the results of the two kinds of analysis are very similar to each other. Thus it is proper to draw the final conclusions of the factors for successful Chinese neologism diffusion as follows:

Firstly, the most important factors for the diffusion of neologisms are the flexibility of transformation of the word itself, the range of audience and the force of the media. If a neologism is flexible enough and can be widely and properly used in different contexts as more as possible, there will be much more possibility that the word can be successfully diffused and finally become a buzzword by the strong force of the media, which can bring larger range of audience in return.[3]

Secondly, it is also necessary for a neologism to be properly used in the original context and owns a relatively close relation to the society and culture. The proper and interesting usage of a neologism can impress the audience at the beginning. And the close relation to the modern society and culture can bring more empathy to the public.

Finally, the subjects of the communication who are regarded as the information emitter are relatively less important to the effect of the diffusion of Chinese neologisms. In another word, the fame and social status of the subject are not the indispensible elements in the communicative process of transforming a neologism into a buzzword.[4]

However, there still exists limitation of this research. The six items cannot cover all the aspects that may affect the result of the neologism diffusion. Since a word cannot be used totally independently, it will be affected by the environment. Definitely, there are still some factors influencing the spreading process of a word except the six items mentioned above. For example, the gestures and expression of the speaker can also make work. Since it is not easy to find out the state of the participants at the particular moment, this factor is not taken into the consideration.

\section{References}

[1] Dirk Geeraerts, 2012, Cognitive Linguistics: Basic Readings[M], Shanghai : Shanghai Translation publishing house.

[2] Duanpeng,2008, Research on Communication -effect: Communication, development and application[M], Beijing: Communication University of China press.

[3] Elizabeth Closs Traugott, Richard B. Dasher, 2005, Regularity in Semantic Change[M], Cambridge, U.K.; New York: Cambridge University Press.

[4] Rochelle Lieber, 2004, Morphology and Lexical Semantics[M], Cambridge, UK; New York: Cambridge University Press.

[5] Roger Lass, 2007, Historical Linguistics and Language Change[M], Beijing: World Publishing Corporation. 